\title{
Vagus nerve stimulation for children with treatment-resistant epilepsy: a consecutive series of 141 cases
}

\author{
Clinical article
}

\author{
Robert E. Elliott, M.D., ${ }^{1}$ Shaun D. Rodgers, M.D., ${ }^{1}$ Luigi Bassani, M.D., 1 \\ Amr Morsi, M.D., ${ }^{1}$ Eric B. Geller, M.D., ${ }^{2}$ Chad Carlson, M.D., 3 \\ OrRin Devinsky, M.D., ${ }^{1,3,4}$ AND Werner K. Doyle, M.D. ${ }^{1}$ \\ Departments of ${ }^{1}$ Neurosurgery, ${ }^{3}$ Neurology, and ${ }^{4}$ Psychiatry, New York University Langone Medical Center, \\ New York, NewYork; and ${ }^{2}$ Department of Neurology, Saint Barnabas Medical Center, Livingston, New Jersey
}

\begin{abstract}
Object. The authors undertook this study to analyze the efficacy of vagus nerve stimulation (VNS) in a large consecutive series of children 18 years of age and younger with treatment-resistant epilepsy and compare the safety and efficacy in children under 12 years of age with the outcomes in older children.

Methods. The authors retrospectively reviewed 141 consecutive cases involving children ( 75 girls and 66 boys) with treatment-resistant epilepsy in whom primary VNS implantation was performed by the senior author between November 1997 and April 2008 and who had at least 1 year of follow-up since implantation. The patients' mean age at vagus nerve stimulator insertion was 11.1 years (range 1-18 years). Eighty-six children (61.0\%) were younger than 12 years at time of VNS insertion (which constitutes off-label usage of this device).

Results. Follow-up was complete for $91.8 \%$ of patients and the mean duration of VNS therapy in these patients was 5.2 years (range 25 days-11.4 years). Seizure frequency significantly improved with VNS therapy (mean reduction $58.9 \%, \mathrm{p}<0.0001$ ) without a significant reduction in antiepileptic medication burden (median number of antiepileptic drugs taken 3, unchanged). Reduction in seizure frequency of at least $50 \%$ occurred in $64.8 \%$ of patients and $41.4 \%$ of patients experienced at least a $75 \%$ reduction. Major (3) and minor (6) complications occurred in 9 patients $(6.4 \%)$ and included 1 deep infection requiring device removal, 1 pneumothorax, 2 superficial infections treated with antibiotics, 1 seroma/hematoma treated with aspiration, persistent cough in 1 patient, severe but transient neck pain in 1 patient, and hoarseness in 2 patients. There was no difference in efficacy or complications between children 12 years of age and older (FDA-approved indication) and those younger than 12 years of age (off-label usage). Linear regression analyses did not identify any demographic and clinical variables that predicted response to VNS.

Conclusions. Vagus nerve stimulation is a safe and effective treatment for treatment-resistant epilepsy in young adults and children. Over 50\% of patients experienced at least 50\% reduction in seizure burden. Children younger than 12 years had a response similar to that of older children with no increase in complications. Given the efficacy of this device and the devastating effects of persistent epilepsy during critical developmental epochs, randomized trials are needed to potentially expand the indications for VNS to include younger children.
\end{abstract} (DOI: $10.3171 / 2011.2$.PEDS10505)

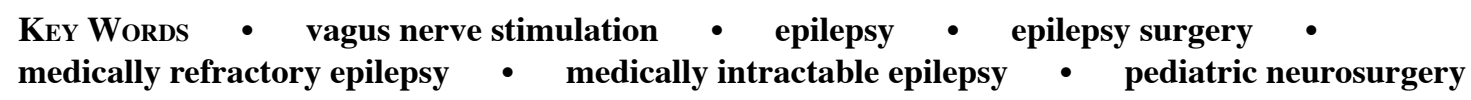

$\mathrm{T}$ He prevalence of epilepsy is $0.5 \%-1 \%$ in the pediatric population, affecting millions of children and young adults worldwide. ${ }^{17,39,51}$ Although most patients are successfully treated with one or more AEDs, treatment-resistant epilepsy occurs in up to one-third of children with epilepsy and can be devastating to children and their families. ${ }^{10,20,25,29,41,46}$

\footnotetext{
Abbreviations used in this paper: $\mathrm{AED}=$ antiepileptic drug; $\mathrm{EEG}$ $=$ electroencephalography; VNS = vagus nerve stimulation.
}

Severe epilepsy is associated with cognitive decline and can be profound in children, disrupting developmental epochs essential to intellectual and social maturation. ${ }^{14,49}$ Retrospective studies in children with epilepsy suggest that better seizure control facilitates developmental progress and improves cognitive outcomes and quality of life. . $^{13,18,31,54}$

Surgical treatment options include resective surgery, disconnection procedures, and stimulation procedures. The most widely used and studied neurostimulation procedure is vagus nerve stimulation (VNS). In 1997, the US 
FDA approved VNS for the treatment of intractable partial epilepsy in adults and children over 12 years of age. The initial randomized studies of VNS were time-limited (3-month follow-up) and demonstrated a $25 \%-30 \%$ decrease in seizure frequency, ${ }^{8,21,23}$ but subsequent nonblinded, nonrandomized studies reported superior seizure control and demonstrated the efficacy and safety of VNS in adults and children with generalized epilepsy. $7,9,25,36,38,41$

Most studies of VNS in children have involved a limited number of patients, often with only a short duration of follow-up. We report 141 consecutive cases involving children who underwent long-term VNS therapy for refractory epilepsy, analyze the efficacy and safety of VNS therapy, and examine predictors of VNS treatment success.

\section{Methods}

\section{Patient Population}

Between November 1997 and April 2008, 154 children (younger than 18 years of age) underwent VNS operations performed at the New York University and Saint Barnabas Medical Center Comprehensive Epilepsy Centers by a single surgeon (W.K.D.). Thirteen patients were referred for removal or revision of a device placed at other centers; 141 consecutive children with treatment-resistant epilepsy underwent primary insertion of a VNS device at our center and are reported on here. At the initial office visit, all patients were prospectively entered into a clinical registry, whose creation was approved by the New York University institutional review board. Data collected included demographic information, surgical history, physical and neurological examination findings, epilepsy characteristics, mean weekly seizure frequency (obtained from seizure logs), treatment history, and imaging findings. This report represents a retrospective analysis of this database.

Each patient underwent a presurgical evaluation that included history and physical examination, EEG, MR imaging and in most cases video EEG and functional imaging studies. Most children were reviewed at a presurgical multidisciplinary conference and deemed to be surgical candidates (Table 1). Selection criteria for the patients who had VNS insertion included patients who have failed multiple AEDs (typically at least 3 AEDs) with multifocal or diffuse seizure onsets not amenable to surgical resection, patients with persistent or recurrent seizures following intracranial epilepsy surgery, AED toxicity or intolerable side effects, patients medically unfit for intracranial surgery and patient or family preference for conservative measures prior to or in lieu of possible intracranial surgery was the selection criterion for VNS therapy. The multidisciplinary conference recommended VNS for the treatment of treatment-resistant epilepsy in 112 children and recommended intracranial epilepsy surgery for 29 children. Seventeen patients underwent intracranial epilepsy surgery and subsequently had VNS implantation due to persistent epilepsy (10 with nonresectable foci; 7 who underwent resection but had persistent or recurrent epilepsy). The families of 12 children chose VNS instead of recommended intracranial surgery.
TABLE 1: Multidisciplinary conference recommendations for 141 children with treatment-resistant epilepsy*

\begin{tabular}{cc}
\hline \multicolumn{1}{c}{ Recommendation } & $\begin{array}{c}\text { No. of Pts } \\
(\%)\end{array}$ \\
\hline VNS & $112(79.4)$ \\
as primary treatment & 103 \\
after failure of intracranial op & 9 \\
intracranial op & $17(12.1)$ \\
bilat electrode monitoring & 10 \\
multistage electrode monitoring/resection & 7 \\
intracranial op/patient or family preference for VNS & $12(8.5)$ \\
bilat electrode monitoring & 2 \\
multistage electrode monitoring/resection & 8 \\
callosotomy & 2 \\
\hline
\end{tabular}

* Pts = patients.

Following institutional review board approval, patients undergoing VNS procedures were identified from within the database. Missing data were obtained from office and inpatient charts, operative reports, imaging and electrophysiological studies. Informed consent for this retrospective analysis was waived by the review board.

\section{Surgical Procedure and Outcome Assessment}

The surgical techniques for subcutaneous and subpectoral implantation of the VNS device have been previously described. ${ }^{5}$ Most children who underwent VNS implantation were discharged the same day. In the remaining cases the children were admitted to the epilepsy monitoring unit as planned for medication adjustment coinciding with VNS surgery. Since 1999, the stimulators were turned on at the time of surgery without adverse sequelae. Surgical follow-up typically occurred 2 weeks postoperatively and subsequently on a variable schedule as indicated. Long-term follow-up and adjustments of VNS parameters were conducted by the epileptologist.

Retrospective chart review was performed to collect follow-up and outcome data. At the time of last available clinical follow-up, the following data were collected: mean weekly seizure frequency (calculated from seizure logs kept by caretakers as an average of weekly frequencies from last 2 office visits or as an average of weekly frequencies over the 3 months prior to the visit), complications of VNS therapy, duration of VNS therapy, the timing and reason for revisions and removals of VNS devices, and all subsequent surgical procedures. A standardized questionnaire addressing complications and side effects was completed at each follow-up visit at our centers.

Telephone interviews were conducted with patients, families, or caretakers to determine most recent seizure frequency and current AED regimen. For patients who underwent device removal or had their devices turned off, the time of VNS therapy termination was used as the time of last follow-up. Given the demonstration of VNS effect by 3 months from the randomized trials, we considered patients who had VNS therapy for at least 3 months with 
clinical follow-up data to have adequate follow-up. Patients who did not have follow-up of at least 3 months were excluded from outcome analyses.

Postoperative seizure outcomes assessed at the time of the last follow-up are expressed with a modified Engel scale $^{16}$ and with a VNS-specific outcome scale proposed by $\mathrm{McHugh}$ et al. ${ }^{34}$

Some children reported in this study were included in prior studies by our group on subpectoral and subcutaneous VNS generator placement ${ }^{5}$ (49 children) and VNS in patients with tuberous sclerosis complex ( 9 children). ${ }^{15}$

Vagus nerve stimulation therapy in patients with generalized epilepsies and children under 12 years of age is an off-label usage not approved by the US FDA.

\section{Statistical Analyses}

Averages are expressed as means \pm SDs. Seizure frequency and number of AEDs before and after VNS lacked normal distributions; therefore, median values are reported and the paired-samples Wilson signed-ranks test was employed to analyze pre- and postoperative seizure frequency and AED requirements (nonparametric data). Univariate and multivariate linear regression analyses were performed to determine the impact of the following independent variables (continuous, dichotomous, or multinomial) on mean percentage seizure reduction (dependent variable): age at epilepsy onset, age 5 years or less at onset of epilepsy (dichotomous), age at VNS implantation, age $\geq 12$ years at VNS implantation (dichotomous), duration of epilepsy prior to VNS, duration of epilepsy > 10 years prior to VNS therapy (dichotomous), prior intracranial epilepsy surgery (dichotomous), number of prior intracranial epilepsy surgery procedures, preimplantation seizure frequency, number of reported seizure types, partial seizures only (dichotomous), epilepsy classification and etiology (multinomial), underlying diagnosis if applicable (multinomial), EEG findings (multinomial; focal, multifocal, diffuse, diffuse and multifocal), number of preimplantation AEDs, number of failed AEDs and history of infantile spasms, febrile seizures, and developmental delay or status epilepticus (dichotomous variables). All statistical analyses were performed using SPSS 17.0 for Mac (SPSS Inc.). A p value $<0.05$ was considered statistically significant.

\section{Results}

\section{Demographic and Clinical Data}

Demographic characteristics and clinical data for the 141 patients who had primary implantations are summarized in Table 2. The group included 75 girls (53.2\%) and 66 boys (46.8\%), and the patients' ages at VNS implantation ranged from 1.3 to 18 years (mean $11.1 \pm 4.7$ years). Eighty-six children $(61.0 \%)$ were younger than 12 years at time of VNS insertion (off-label usage).

The mean age at seizure onset for the cohort was 2.8 \pm 3.6 years (range birth-16 years) and the mean duration of epilepsy prior to VNS therapy initiation was $8.4 \pm$ 4.4 years (range 1 week-17.9 years). The median weekly seizure frequency was 10 seizures (range 0.1-2000 sei-
TABLE 2: Demographic and clinical data for 141 children who underwent VNS for treatment-resistant epilepsy

\begin{tabular}{|c|c|}
\hline Variable & Value $^{*}$ \\
\hline \multicolumn{2}{|l|}{ sex } \\
\hline $\mathrm{F}$ & $75(53.2)$ \\
\hline M & $66(46.8)$ \\
\hline \multicolumn{2}{|l|}{ age at seizure onset (yrs) } \\
\hline mean & $2.8 \pm 3.6$ \\
\hline range & birth-16 yrs \\
\hline \multicolumn{2}{|l|}{ duration of epilepsy prior to VNS } \\
\hline mean (yrs) & $8.4 \pm 4.4$ \\
\hline range & 7 days -17.9 yrs \\
\hline \multicolumn{2}{|l|}{ age at VNS insertion (yrs) } \\
\hline mean & $11.1 \pm 4.7$ \\
\hline range & $1.3-18$ \\
\hline \multicolumn{2}{|l|}{ pt age } \\
\hline$<12$ yrs $†$ & $86(61.0)$ \\
\hline$\geq 12 \mathrm{yrs}$ & $55(39.0)$ \\
\hline \multicolumn{2}{|l|}{ seizure frequency (no. per wk) } \\
\hline median & 10 \\
\hline range & $0.1-2000$ \\
\hline \multicolumn{2}{|l|}{ no. of AEDs } \\
\hline mean & $2.6 \pm 0.9$ \\
\hline range & $1-7$ \\
\hline \multicolumn{2}{|l|}{ no. of AEDs failed } \\
\hline mean & $5.5 \pm 2.9$ \\
\hline range & 2-15 \\
\hline prior failed intracranial epilepsy surgery & $30(21.3)$ \\
\hline \multicolumn{2}{|l|}{ no. of seizure types } \\
\hline mean & $2.2 \pm 1.1$ \\
\hline range & $1-6$ \\
\hline developmental delay & $112(79.4)$ \\
\hline
\end{tabular}

* Values represent numbers of patients (\%) unless otherwise indicated. $\dagger$ Off-label usage.

zures) and the mean number of seizure types was $2.2 \pm$ 1.1 (range 1-6 types). Treatment with an average of $5.5 \pm$ 2.9 AEDs (range 2-15 AEDs) had failed in these children prior to VNS insertion and the children were taking an average of $2.6 \pm 0.9$ AEDs (range 1-7 AEDs) at time of insertion. Thirty patients $(21.3 \%)$ had undergone a total of 38 intraoperative epilepsy surgery procedures prior to VNS therapy. One hundred twelve patients (79.4\%) had developmental delay or neurocognitive impairment.

The classification of epilepsy type, EEG findings, and underlying etiologies in these children are summarized in Table 3 . The most common types of epilepsy were multifocal partial epilepsy (39.0\%), symptomatic generalized epilepsy $(29.1 \%)$ and idiopathic generalized epilepsy $(13.5 \%)$. The most common EEG findings were multifocal (44.0\%) or diffuse/generalized (43.3\%) onsets. Excluding children with unknown etiologies, the most common underlying diagnoses were cerebral palsy/static encephalopathy (10.6\%), neuronal migration disorders/ 
TABLE 3: Epilepsy classification, EEG findings, and etiology in 141 children treated with VNS for treatment-resistant epilepsy*

\begin{tabular}{lc}
\hline \multicolumn{1}{c}{ Variable } & No. of Pts (\%) \\
\hline epilepsy classification & \\
MFPE & $55(39.0)$ \\
SGE & $41(29.1)$ \\
IGE & $19(13.5)$ \\
MFPE/SGE & $18(12.8)$ \\
focal (frontal or temporal) & $5(3.5)$ \\
myoclonic epilepsy & $2(1.4)$ \\
EEG findings & \\
focal & $5(3.5)$ \\
multifocal & $62(44.0)$ \\
diffuse/generalized & $61(43.3)$ \\
diffuse/multifocal & $13(9.2)$ \\
epilepsy etiology & \\
idiopathic & $54(38.3)$ \\
cerebral palsy/static encephalopathy & $15(10.6)$ \\
neuronal migration disorders & $14(9.9)$ \\
infection & $13(9.2)$ \\
LGS & $11(7.8)$ \\
TSC & $8(5.7)$ \\
genetic/metabolic disorders & $14(9.9)$ \\
vascular lesion/tumor & $3(2.1)$ \\
TBI & $3(2.1)$ \\
LKS & $4(2.8)$ \\
HH & $2(1.4)$ \\
\hline
\end{tabular}

* $\mathrm{HH}=$ hypothalamic hamartoma; IGE = idiopathic generalized epilepsy; LGS = Lennox-Gastaut syndrome; LKS = Landau-Kleffner syndrome; MFPE = multifocal partial epilepsy; SGE = symptomatic generalized epilepsy; $\mathrm{TBI}$ = traumatic brain injury; $\mathrm{TSC}$ = tuberous sclerosis complex.

dysplasia (9.9\%), genetic/metabolic disorders (9.9\%), and infection (9.2\%; encephalitis and/or meningitis).

\section{Seizure Control Outcomes and Follow-Up}

The mean duration of VNS therapy was $5.3 \pm 3.1$ years for the entire cohort (range 25 days-11.4 years). Two patients died during the follow-up period, and both deaths were related to the patients' epilepsy (21 months and 10 years following implantation). Eleven US patients and 2 patients from other countries had less than 3 months' postoperative follow-up and were unreachable by phone. Excluding these 13 patients with inadequate follow-up, data from 128 patients $(91.8 \%)$ were available for outcome analyses. There were no significant differences between children with and without adequate follow-up in terms of sex distribution, age at seizure onset, duration of seizures, age at stimulator insertion, seizure types, seizure frequency, EEG findings, or past or present AED usage ( $p>0.05$ for all comparisons).

The mean percentage seizure reduction in these 128 children was $57.9 \%$ (range $0 \%-100 \%$ ). The median weekly seizure frequency was 3 , significantly decreased from their preoperative baseline of 10 seizures per week $(\mathrm{p}<0.0001)$. There was no significant difference in number of AEDs taken at time of last follow-up compared to the number taken preoperatively (median 3 , range $0-7$, for both; $p=0.15$ ). Following VNS therapy, 26 children (20.3\%) were taking fewer AEDs, 62 patients (48.4\%) were taking the same number of AEDs, and 40 patients $(31.2 \%)$ were taking a greater number of AEDs at last follow-up. Changes in AED regimen (medication and/or dosage) or stimulation parameters were made at many office visits.

Table 4 summarizes the seizure control outcomes by modified Engel and McHugh classifications. Excluding 13 patients who lacked adequate follow-up, $\geq 90 \%$ seizure control was achieved in 27 patients $(21.1 \%), \geq 75 \%$ seizure control in 53 patients $(41.4 \%), \geq 50 \%$ seizure control in 83 patients $(64.8 \%)$, and $<50 \%$ seizure control in 45 patients $(35.2 \%)$. Ten patients $(7.8 \%)$ experienced no reduction in seizure burden and 3 patients $(2.3 \%)$ had an increase in seizure activity from their presurgical baseline. Ten patients $(7.8 \%)$ have remained seizure-free for at least 6 months prior to the last follow-up visit.

Vagus nerve stimulation resulted in a significant reduction in seizure frequency regardless of epilepsy type, etiology, and EEG findings (Table 5). Univariate linear regression analyses did not identify any demographic or clinical variables that predicted response to VNS; therefore, multivariate analysis was not performed.

\section{Surgical Results and Complications}

The leads were placed on the left vagus nerve in all patients. Generators were placed subpectorally in 91 patients $(64.5 \%)$ and subcutaneously in 50 patients $(35.5 \%)$. There were no urgent readmissions for acute complications or sequelae from same-day discharge.

The most common side effect was mild but tolerable neck pain associated with the duty cycle, which occurred in $18 \%$ of children. In all but a few cases, this resolved spontaneously over the course of a few weeks or with adjustment of the stimulation parameters.

Table 6 summarizes the neurological and nonneurological complications that occurred consequent to VNS implantation. Transient or minor neurological side effects included hoarseness in 1 child $(0.7 \%)$, which resolved by 3 months, and intractable cough during stimulation in 1 child $(0.7 \%)$. One child $(0.7 \%)$ experienced moderate, permanent hoarseness. No child experienced dysphagia or vocal cord paralysis. Minor nonneurological complications included neck and arm pain unrelated to the duty cycle in 2 patients $(0.5 \%)$ and neck pain related to the duty cycle in 1 patient $(0.7 \%)$. In all 5 patients, the pain improved over time but persisted at a low level that was tolerable for them. Two patients (1.4\%) developed superficial wound infections that were treated successfully with antibiotics alone and 1 patient developed a hematoma/ seroma that was successfully treated with aspiration. Two children (1.4\%) developed significant complications including infection requiring device removal in 1 case $(0.7 \%)$ and pneumothorax in the other $(0.7 \%)$. There was no difference in the incidence of major or minor com- 
TABLE 4: Seizure control outcomes by modified Engel and McHugh outcome classifications following VNS therapy in 128 children with complete follow-up*

\begin{tabular}{|c|c|c|c|c|}
\hline Class & Modified Engel Description & No. of Pts (\%) & McHugh Description & No. of Pts $(\%)$ \\
\hline I & seizure-free; rare, nondisabling SPS & $15(11.7)$ & $\begin{array}{l}80 \%-100 \% \text { reduction in seizure } \\
\text { frequency }\end{array}$ & $42(32.8)$ \\
\hline$\|$ & $>90 \%$ reduction in seizure frequency; rare CPS & $14(10.9)$ & $\begin{array}{l}50 \%-79 \% \text { reduction in seizure } \\
\text { frequency }\end{array}$ & $41(32.0)$ \\
\hline III & $50 \%-90 \%$ reduction in seizure frequency & $54(42.2)$ & $<50 \%$ reduction in seizure frequency & $30(23.4)$ \\
\hline IV & $<50 \%$ reduction in seizure frequency & $45(35.1)$ & magnet benefit only & $2(1.6)$ \\
\hline V & - & - & no improvement & $13(10.2)$ \\
\hline
\end{tabular}

* CPS = complex partial seizure; SPS = simple partial seizure.

plications between children 12 years of age or older and those younger than 12 years of age (2 [3.6\%] of 55 vs 1 [1.2\%] of $86, p=0.56$, and 3 [5.5\%] of 55 vs 3 [3.5\%] of $86, \mathrm{p}=0.69$, respectively).

\section{Device Revisions and Removals}

Forty-nine patients (34.8\%) underwent a total of 61 device revisions after primary implantation at our center. Forty children had 1 revision, 9 children had 2 revisions, and 1 child had 3 revisions during the follow-up period. Of the 61 revision procedures, generator changes alone were performed in 51 cases and complete revision (generator and lead) in 10 cases. The most common indication for revision was generator power depletion, and it occurred at a

\section{TABLE 5: Median seizure reduction by epilepsy classification, etiology, and EEG findings*}

\begin{tabular}{lrcr}
\hline \multicolumn{1}{c}{ Variable } & $\begin{array}{c}\text { No. of } \\
\text { Pts }\end{array}$ & $\begin{array}{c}\text { Median Sz } \\
\text { Reduction (\%) }\end{array}$ & p Value† \\
\hline epilepsy classification & & & \\
$\quad$ focal & 5 & 86.2 & 0.042 \\
MFPE & 55 & 50.0 & $<0.001$ \\
MFPE/SGE & 18 & 72.0 & $<0.001$ \\
SGE & 41 & 62.5 & $<0.001$ \\
IGE & 19 & 66.7 & 0.003 \\
epilepsy etiology & & & \\
neuronal migration disorder & 14 & 50.0 & 0.001 \\
CP/static encephalopathy & 15 & 68.9 & 0.016 \\
LGS & 11 & 51.0 & 0.008 \\
infection & 13 & 45.0 & 0.012 \\
TSC & 8 & 75.0 & 0.018 \\
genetic/metabolic syndrome & 14 & 66.7 & 0.003 \\
unknown & 54 & 65.0 & $<0.001$ \\
EEG findings & & & \\
focal & 5 & 86.2 & 0.042 \\
multifocal & 62 & 54.6 & $<0.001$ \\
diffuse & 61 & 64.8 & $<0.001$ \\
multifocal \& diffuse & 13 & 68 & 0.002 \\
\hline
\end{tabular}

* $\mathrm{CP}=$ cerebral palsy; $\mathrm{Sz}=$ seizure.

$\dagger$ Analyzed via paired-samples Wilson signed-rank test. mean of $41.3 \pm 18.1$ months following implantation or last generator change (range 6.3-106 months). Lead fracture occurred in 4 devices, and the patients presented with delayed neck pain in synchrony with the duty cycle. In 2 patients, the indication for device revision included hardware displacement associated with an adolescent growth spurt. There were no complications following revision surgery.

At revision, generators were maintained in the subcutaneous location in 32 cases, maintained in the subpectoral location in 21 cases, and moved to a subpectoral location for improved cosmesis in 7 cases. A very short segment of the lead containing the electrodes is left attached to the vagus nerve during lead revisions.

Twenty-one children (14.9\%) underwent device removal following primary insertion at our center at a mean time of $43.4 \pm 29.4$ months after insertion (range 8.5 months-9.5 years). Indications for device removal were nonefficacy (in 8 cases), MR imaging for possible or planned intracranial surgery (in 11 cases), infection (in 1 case), and AED success (in 1 case). There were no complications during device removal.

\section{Discussion}

Among 141 children with treatment-resistant epilepsy who underwent VNS device implantation, a 50\% or greater reduction in seizure burden was achieved in over half of patients. While many patients noted hoarseness or pain during stimulation and the ramp-up period, most of these side effects resolved with time or alteration of stimulation parameters. Serious complications causing permanent neurological injury or leading to device removal were few $(<3 \%)$. Vagus nerve stimulation worked well for all types of epilepsy and age groups, including non-FDA approved indications like generalized epilepsies and in children under the age of 12 years. Purported markers of more severe epilepsy, such as duration of seizures, number of seizure types, number of failed AEDs, and failure of intracranial epilepsy surgery, did not correlate with VNS success.

\section{Seizure Control and Development}

Severe treatment-resistant epilepsy is associated with cognitive decline. ${ }^{14,49}$ In children with treatment-resistant epilepsy, better seizure control can result in improved 
R. E. Elliott et al.

TABLE 6: Minor and major complications following VNS implantation in 141 children with treatment-resistant epilepsy*

\begin{tabular}{|c|c|c|c|c|c|c|}
\hline \multirow[b]{2}{*}{ Complication } & \multicolumn{2}{|c|}{$<12$ Yrs of Age (86 pts) } & \multicolumn{2}{|c|}{$\geq 12$ Yrs of Age (55 pts) } & \multicolumn{2}{|c|}{ Total } \\
\hline & Minor & Major & Minor & Major & Minor & Major \\
\hline neurological & 2 & 0 & 0 & 1 & $2(1.4)$ & $1(0.7)$ \\
\hline hoarseness & 1 & - & - & 1 & $1(0.7)$ & $1(0.7)$ \\
\hline intractable cough & 1 & - & - & - & $1(0.7)$ & - \\
\hline nonneurological & 1 & 1 & 3 & 1 & $4(2.8)$ & $2(1.4)$ \\
\hline neck pain related to duty cycle & - & - & 1 & - & $1(0.7)$ & - \\
\hline superficial infection (antibiotics) & 1 & - & 1 & - & $2(1.4)$ & - \\
\hline deep infection (removal/revision) & - & 1 & - & - & - & $1(0.7)$ \\
\hline seroma/hematoma requiring aspiration & - & - & 1 & - & $1(0.7)$ & - \\
\hline pneumothorax & - & - & - & 1 & - & $1(0.7)$ \\
\hline subtotals & $3(3.5)$ & $1(1.2)$ & $3(5.5)$ & $2(3.6)$ & $6(4.2)$ & $3(2.1)$ \\
\hline
\end{tabular}

*Values represent numbers of patients (\%). Minor complications were those that were managed conservatively or resolved spontaneously. Major complications included permanent neurological deficits or complications that required device removal or other invasive procedures.

developmental and cognitive outcome and quality of life. ${ }^{13,18,27,28,31,54}$ Moreover, numerous studies found that VNS can benefit attention, cognition, behavior, mood, and quality of life independent of reduced seizure burden. $1,22,24,25,35,41$ These findings suggest that consideration of VNS earlier in the course of refractory disease is warranted..$^{42}$

No randomized studies have demonstrated long-term benefits of VNS therapy on cognitive, social, or behavioral development or quality of life. However, it is uniformly believed that reduction in seizure burden during the critical early development of children will yield important benefits in long-term functional outcome. Although some patients in our series experienced improvements in development and behavior, formal preoperative and postoperative neuropsychological assessments were not available to quantify this benefit.

\section{Efficacy of VNS}

Although most studies on the efficacy of VNS have involved adult patients, many smaller pediatric series have shown comparable results (Table 7). 1,2, , 15,25,26,30,33,36-38, $40,41,43,45,47,52,53$ Like other authors, ${ }^{25,36,38,41}$ we found no difference in VNS efficacy in children younger than 12 years compared with older children. Analyzing the efficacy of VNS in children, Levy et al. ${ }^{30}$ retrospectively queried the Cyberonics, Inc. registry and noted a mean reduction in seizure frequency of more than $55 \%$ at 12 months of therapy. After 3 and 6 months of VNS treatment, Helmers et al. ${ }^{25}$ found that children exhibited a mean reduction in seizure burden of $36 \%$ and $45 \%$, respectively. Murphy and colleagues ${ }^{38}$ also reported at least $50 \%$ reduction in seizure burden in $45 \%$ of 100 children with treatmentresistant epilepsy at a median follow-up of 32 months. Alexouploulos and colleagues ${ }^{2}$ reported a mean reduction in seizure burden of $60 \%$ and a $>75 \%$ reduction in $43.5 \%$ of patients. Our current study demonstrates similar results with a larger number of patients and a significantly longer follow-up ( $>5$ years).

Cost-savings analyses were performed in small series of cases. ${ }^{6,11,12,32}$ Authors reported significant decreases in hospital admissions, length of stay, intensive care unit admissions, and emergency room visits and estimated that the cost of the device and implantation (roughly $\$ 10,000$ ) can be recovered within 2-3 years after initiation of VNS therapy. ${ }^{6} 11,12,32$ Given the long life expectancy of children, these results may translate into a significant cost savings over time.

Although seizure reduction and hospital costs are the major clinical and economic considerations when considering the cost-effectiveness of any therapy for treatmentresistant epilepsy, other potential benefits may be equally important. Ancillary benefits of seizure control in children include health-related quality of life and cognitive improvements, fewer epilepsy-related injuries, decrease in sudden unexplained death in epilepsy patients (SUDEP), psychological improvements in anxiety and depression, improved school attendance, improvements in social and interpersonal relationships, and decrease in AED burden and side effects. ${ }^{4}$

\section{Complications and Cosmetic Considerations}

Dysphonia, throat or neck pain, and cough during stimulation are the most commonly reported side effects of VNS. Typically, these symptoms abate with time or alteration of the stimulation parameters. . $^{2,3,19,36,44,50}$ Significant or permanent injuries to the vagus nerve or development of dysphagia following implantation were rare $(<$ $0.5 \%$ ) in our series, and the rate is comparable to rates reported for other series $(\leq 4 \%)$. The rate of infection was under $3 \%$, which is comparable to rates reported in most large series $(0 \%-8 \%)$ and similar to those reported for other implantable devices. In corroboration of the results reported by Murphy and colleagues, ${ }^{38}$ we found no difference in the rate of adverse effects in children younger than 12 years of age, compared with older children. This documentation of the safety of VNS in younger, smaller children is an important initial step toward expanding the FDA-approved indications for VNS. 


\begin{tabular}{|c|c|c|c|c|c|c|c|c|c|c|c|c|c|c|c|c|}
\hline \multirow[b]{2}{*}{ Authors \& Year } & \multirow{2}{*}{$\begin{array}{l}\text { No. } \\
\text { of } \\
\text { Pts }\end{array}$} & \multirow[b]{2}{*}{ Design } & \multirow{2}{*}{$\begin{array}{c}\mathrm{FU} \\
(\mathrm{mos}) \dagger\end{array}$} & \multirow{2}{*}{$\begin{array}{c}\% S z \\
\text { Reduct } †\end{array}$} & \multicolumn{4}{|c|}{$\%$ Sz Reduct (\% of pts) } & \multirow{2}{*}{$\begin{array}{c}\text { Worse } \\
\text { Szs } \\
(\%)\end{array}$} & \multicolumn{2}{|c|}{$\begin{array}{c}\text { Hoarseness } \\
(\%)\end{array}$} & \multirow{2}{*}{$\begin{array}{c}\text { VC } \\
\text { Paral/ } \\
\text { Dys- } \\
\text { phagia } \\
(\%)\end{array}$} & \multicolumn{2}{|c|}{$\begin{array}{c}\text { Neck/Throat } \\
\text { Pain (\%) }\end{array}$} & \multirow{2}{*}{$\begin{array}{l}\text { Cough } \\
(\%)\end{array}$} & \multirow{2}{*}{$\begin{array}{r}\text { Infec } \\
\text { tion } \\
(\%)\end{array}$} \\
\hline & & & & & $\geq 50$ & $\geq 75$ & $\geq 90$ & 100 & & Trans & Perm & & Trans & tract & & \\
\hline $\begin{array}{l}\text { Murphy et al., } \\
1995\end{array}$ & 12 & $\mathrm{R}$ & 7.4 & - & 25 & 25 & 25 & - & - & 0 & 0 & 0 & 0 & 0 & 0 & 16.7 \\
\hline Hornig et al., 1997 & 19 & $\mathrm{R}$ & 3.5 & - & 53 & - & 32 & 5.3 & 11 & $100 \ddagger$ & 0 & 0 & 0 & 0 & 0 & 0 \\
\hline $\begin{array}{l}\text { Murphy et al., } \\
1999\end{array}$ & 60 & $\mathrm{R}$ & $>18$ & $42 \S$ & - & - & - & - & 6 & 21.7 & 13 & 0 & 0 & 0 & 25 & 18.3 \\
\hline $\begin{array}{l}\text { Patwardhan et al., } \\
2000\end{array}$ & 38 & $\mathrm{R}$ & 12 & - & 68 & - & 29 & - & - & - & - & - & - & - & - & - \\
\hline $\begin{array}{l}\text { Helmers, et al., } \\
2001\end{array}$ & 125 & $\mathrm{R}$ & $3-6$ & 45 & $51 \rrbracket$ & - & - & $0 \pi$ & $2 \pi$ & 57.9 & 0.8 & 0.8 & 1.1 & - & 37.9 & - \\
\hline Parain et al., 2001 & 10 & $\mathrm{R}(\mathrm{TSC})$ & 22 & - & 90 & - & 50 & 0 & 0 & 0 & 0 & 0 & 0 & 0 & $-^{* *}$ & 0 \\
\hline $\begin{array}{l}\text { Aldenkamp et al., } \\
2002\end{array}$ & 19 & $\mathrm{R}(\mathrm{LGS})$ & 24 & 20.6 & 21 & - & - & - & - & - & - & - & - & - & - & - \\
\hline $\begin{array}{l}\text { Zamponi et al., } \\
2002\end{array}$ & 13 & $\mathrm{R}$ & 13.6 & $66+\dagger$ & $77 \dagger \dagger$ & - & - & 0 & 0 & $-\dagger \dagger$ & 0 & 0 & 7.7 & 0 & - & 0 \\
\hline $\begin{array}{l}\text { Murphy et al., } \\
2003\end{array}$ & 100 & $\mathrm{R}$ & 32.4 & - & 45 & - & 29 & 18 & 5 & - & 1 & 0 & - & - & - & 3 \\
\hline Smyth et al., 2003 & 74 & $\mathrm{R}$ & 26.4 & - & - & - & - & - & - & 1.4 & 0 & 1.4 & 0 & 0 & 1.4 & 7.1 \\
\hline $\begin{array}{l}\text { Major \& Thiele, } \\
2005\end{array}$ & 12 & $\mathrm{R}(\mathrm{TSC})$ & 52.4 & - & 50 & - & - & 0 & 0 & 0 & 0 & 0 & 8.3 & 0 & 8.3 & 16.7 \\
\hline $\begin{array}{l}\text { Alexopoulos et al., } \\
2006\end{array}$ & 49 & $\mathrm{R}$ & 24 & 60 & 59 & 43.5 & - & 10.1 & - & $-\ddagger \ddagger$ & 0 & 0 & 一 $\ddagger$ & 0 & - & 0 \\
\hline Benifla et al., 2006 & 41 & $\mathrm{R}$ & 31 & - & 41.5 & - & 38 & - & 0 & 14.6 & 2.4 & 0 & - & 2.4 & 14.6 & 4.9 \\
\hline $\begin{array}{l}\text { Rychlicki et al., } \\
2006\end{array}$ & 34 & $\mathrm{R}$ & 30.8 & $49 ף(61 \S \S)$ & - & - & - & 8.8 & - & 44.1 & 0 & 4 & 11.8 & 0 & - & 0 \\
\hline $\begin{array}{l}\text { Zamponi et al., } \\
2008\end{array}$ & 6 & $\begin{array}{c}\text { age }<3 \\
\text { yrs }\end{array}$ & 41.6 & 50.8 & 50 & 33.3 & 16.7 & 0 & 0 & 0 & 0 & 0 & 0 & 0 & 0 & 0 \\
\hline $\begin{array}{l}\text { Rossignol et al., } \\
2008\end{array}$ & 28 & $\mathrm{R}$ & 24 & $53 \S \S$ & 68 & - & - & 14 & - & -ाா & - & 4.2 & -ा币 & - & -१币 & 8.3 \\
\hline $\begin{array}{l}\text { Shahawan et al., } \\
2009\end{array}$ & 26 & $\mathrm{R}$ & 36 & - & 54 & 31 & 11.5 & 3.8 & 0 & 3.8 & 0 & 3.8 & 7.7 & 3.8 & - & 0 \\
\hline Elliott et al., 2009 & 8 & $\mathrm{R}(\mathrm{TSC})$ & 38.1 & 71.3 & 87.5 & 78.1 & 25 & 12.5 & 0 & 0 & 0 & 0 & 25 & 12.5 & 0 & 0 \\
\hline \multicolumn{17}{|l|}{ Levy et al., 2010a } \\
\hline Group A & 315 & registry & 12 & 55.6 & 48.6 & 28.3 & 15.9 & 4.4 & 21.6 & - & - & - & - & - & - & - \\
\hline Group B & 78 & registry & 12 & 62.5 & 48.7 & 29.5 & 18 & 5.1 & 19.2 & - & - & - & - & - & - & - \\
\hline present study & 141 & $\mathrm{R}$ & 63.6 & 57.9 & 64.8 & 41.4 & 21.1 & 7.8 & 2.3 & 0.7 & 0.7 & 0 & 18 & 2.1 & $0.7^{\mathrm{b}}$ & 2.1 \\
\hline
\end{tabular}

* All studies are retrospective in design. Abbreviations: FU = follow-up; Intract = intractable; Paral = Paralysis; Perm = permanent; $\mathrm{R}=$ retrospective; Reduct $=$ Reduction; Trans $=$ transient; VC = vocal cord.

$\dagger$ Mean or median values (with exception of duration of follow-up for Helmers et al. [range]).

$\ddagger$ All patients had hoarseness during stimulation only.

$\S$ At 18-month follow-up in 46 of 60 patients.

I At 6-month follow-up.

** Cough occurred when current was being increased but resolved with reduction in current. Number of cases was unreported.

†† At 3-month follow-up. All 13 patients experienced change in vocal timbre during stimulation but this was not a significant problem for the patients.

括 $56.5 \%$ of patients experienced throat pain, hoarseness, cough, or drooling that resolved spontaneously or responded to changes in stimulator settings.

$\S \S$ At 24-month follow-up.

१ף Most children had minor side effects like throat or chest pain, voice change, dyspnea, coughing, or mild dysphagia.

a Study was conducted via retrospective query of the voluntary registry of Cyberonics, Inc., and compared 315 children with treatment-resistant epilepsy (Group A) with 77 children with treatment-resistant epilepsy and autistic spectrum disorder (Group B). Mean seizure reduction recorded at 12 months following implantation.

b Many children experienced coughing during the ramp-up period but only 1 patient had persistent cough with stimulation. 
Compared with the potential neurological deficits from resective surgeries and the risk of disconnection syndrome from corpus callosotomy, ${ }^{48}$ the relative risks of a "minimally invasive" and fully reversible procedure like VNS implantation are minor, often self-limited and well-tolerated by children. Importantly, the most common adverse effects associated with VNS (cough, voice change, and throat pain during stimulation) are not dangerous to the patient.

Another important factor when choosing VNS in children is the cosmetic impact of having a subcutaneous generator in the infraclavicular region. Children typically have less adipose tissue to cushion the generator and also may tend to tamper with the wound or device. We have previously described our technique for subpectoral insertion of the generator and noted increased soft-tissue coverage, improved cosmesis, lower risk of tampering or trauma, and a comparable risk of infection. We strongly believe the subpectoral technique for generator implantation should be considered in children, especially younger children.

\section{Study Limitations}

Our study was limited by the retrospective query into a prospective database and is subject to biases inherent to such methodology. Nearly $8 \%$ of patients were unavailable for follow-up. Determination of seizure frequency relied on the reports of patients or caretakers and is inherently subject to error and bias. This limitation is common to many studies measuring seizure frequency and treatment outcomes. We tried to improve our estimates by using LVCF (last value carried forward) analysis instead of declining-n analysis, which is prone to nonresponder attrition. ${ }^{50}$

Detailed information on the effects of VNS on mood, quality of life, and qualitative aspects of seizures (duration, severity, clustering, postictal period, and magnet usage) were either not systematically reported or could not be derived from this retrospective analysis. Moreover, we did not determine if a mean reduction in seizures of nearly $50 \%$ translates into caretaker and patient satisfaction and overall improvements in quality of life. Future prospective studies are needed to better ascertain baseline mood assessments, quality-of-life metrics, and caretaker satisfaction and to determine the impact of VNS on these parameters and their relation to seizure control.

Another confound concerns the unknown impact that changes in AED regimens have on seizure frequency over time in the setting of VNS. Many office visits were accompanied by VNS setting changes and, more frequently, by AED regimen adjustments. We could not control for these changes but believe AED treatment plays a major role in the success of any treatment plan, including long-term VNS therapy. Further study is needed to better understand the relative contributions of effective VNS therapy, AED regimen adjustments, and regression to the mean.

To our knowledge, however, this is the largest case series involving VNS therapy in children with the longest reported follow-up duration (mean $>5$ years) in the literature. Our treatment protocol and outcomes arise in the setting of a high-volume epilepsy center using a multidisciplinary approach. Approximately $25 \%-30 \%$ of patients who are deemed surgical candidates at our center undergo VNS instead of intracranial epilepsy surgery. We agree with authors from other centers ${ }^{12,41}$ and stress that VNS - despite its apparent simplicity and safety-should be considered as a palliative treatment option for children with treatment-resistant epilepsy but only after thorough evaluation to exclude those children who may benefit from intracranial surgery.

\section{Conclusions}

Vagus nerve stimulation is a safe and effective palliative treatment option for treatment-resistant partial and generalized epilepsy in children. When it was used as part of a multidisciplinary and multimodality treatment regimen including aggressive AED regimens and epilepsy surgery, more than $50 \%$ of children with treatmentresistant epilepsy experienced at least a $50 \%$ reduction in seizure burden. Given the potential for developmental, cognitive, and behavioral improvement with or without improved seizure control, VNS should be considered early in the course of treatment-resistant epilepsy for possible improved outcomes and quality of life. The rate of complications and VNS efficacy were similar in patients younger than 12 years of age and those 12 years of age or older. Prospective, randomized trials are needed for patients with generalized epilepsies and for younger children to potentially expand the FDA-approved population of patients who may benefit from this palliative treatment.

\section{Disclosure}

The authors report no conflict of interest concerning the materials or methods used in this study or the findings specified in this paper.

Author contributions to the study and manuscript preparation include the following. Conception and design: Elliott, Doyle. Acquisition of data: Elliott, Morsi, Doyle. Analysis and interpretation of data: Morsi, Geller, Carlson, Devinsky, Doyle. Drafting the article: Elliott, Rodgers, Bassani, Morsi, Carlson. Critically revising the article: all authors. Reviewed final version of the manuscript and approved it for submission: all authors. Statistical analysis: Elliott. Administrative/technical/material support: Geller, Devinsky, Doyle. Study supervision: Devinsky, Doyle.

\section{References}

1. Aldenkamp AP, Majoie HJ, Berfelo MW, Evers SM, Kessels AG, Renier WO, et al: Long-term effects of 24-month treatment with vagus nerve stimulation on behaviour in children with Lennox-Gastaut syndrome. Epilepsy Behav 3:475-479, 2002

2. Alexopoulos AV, Kotagal P, Loddenkemper T, Hammel J, Bingaman WE: Long-term results with vagus nerve stimulation in children with pharmacoresistant epilepsy. Seizure 15: 491-503, 2006

3. Amar AP, DeGiorgio CM, Tarver WB, Apuzzo ML: Longterm multicenter experience with vagus nerve stimulation for intractable partial seizures: results of the XE5 trial. Stereotact Funct Neurosurg 73:104-108, 1999

4. Balabanov A, Rossi MA: Epilepsy surgery and vagal nerve stimulation: what all neurologists should know. Semin Neurol 28:355-363, 2008 
5. Bauman JA, Ridgway EB, Devinsky O, Doyle WK: Subpectoral implantation of the vagus nerve stimulator. Neurosurgery 58 (4 Suppl 2): ONS-322-ONS-326, 2006

6. Ben-Menachem E, Hellström K, Verstappen D: Analysis of direct hospital costs before and 18 months after treatment with vagus nerve stimulation therapy in 43 patients. Neurology 59 (6 Suppl 4):S44-S47, 2002

7. Ben-Menachem E, Hellström K, Waldton C, Augustinsson LE: Evaluation of refractory epilepsy treated with vagus nerve stimulation for up to 5 years. Neurology 52:1265-1267, 1999

8. Ben-Menachem E, Mañon-Espaillat R, Ristanovic R, Wilder BJ, Stefan H, Mirza W, et al: Vagus nerve stimulation for treatment of partial seizures: 1. A controlled study of effect on seizures. Epilepsia 35:616-626, 1994

9. Benifla M, Rutka JT, Logan W, Donner EJ: Vagal nerve stimulation for refractory epilepsy in children: indications and experience at The Hospital for Sick Children. Childs Nerv Syst 22:1018-1026, 2006

10. Berg AT, Shinnar S, Levy SR, Testa FM, Smith-Rapaport S, Beckerman B: Early development of intractable epilepsy in children: a prospective study. Neurology 56:1445-1452, 2001

11. Boon P, Vonck K, D'Have M, O'Connor S, Vandekerckhove T, De Reuck J: Cost-benefit of vagus nerve stimulation for refractory epilepsy. Acta Neurol Belg 99:275-280, 1999

12. Boon P, Vonck K, Vandekerckhove T, D'have M, Nieuwenhuis L, Michielsen G, et al: Vagus nerve stimulation for medically refractory epilepsy; efficacy and cost-benefit analysis. Acta Neurochir (Wien) 141:447-453, 1999

13. Curatolo P, Verdecchia M, Bombardieri R: Vigabatrin for tuberous sclerosis complex. Brain Dev 23:649-653, 2001

14. Dodrill CB: Neuropsychological effects of seizures. Epilepsy Behav 5 (Suppl 1):S21-S24, 2004

15. Elliott RE, Carlson C, Kalhorn SP, Moshel YA, Weiner HL, Devinsky O, et al: Refractory epilepsy in tuberous sclerosis: vagus nerve stimulation with or without subsequent resective surgery. Epilepsy Behav 16:454-460, 2009

16. Engel JJ: Surgical Treament of the Epilepsies. New York: Raven Press, 1987

17. Eriksson KJ, Koivikko MJ: Prevalence, classification, and severity of epilepsy and epileptic syndromes in children. Epilepsia 38:1275-1282, 1997

18. Freitag H, Tuxhorn I: Cognitive function in preschool children after epilepsy surgery: rationale for early intervention. Epilepsia 46:561-567, 2005

19. Frost M, Gates J, Helmers SL, Wheless JW, Levisohn P, Tardo $\mathrm{C}$, et al: Vagus nerve stimulation in children with refractory seizures associated with Lennox-Gastaut syndrome. Epilepsia 42:1148-1152, 2001

20. Geerts A, Arts WF, Stroink H, Peeters E, Brouwer O, Peters B, et al: Course and outcome of childhood epilepsy: a 15-year follow-up of the Dutch Study of Epilepsy in Childhood. Epilepsia 51:1189-1197, 2010

21. George R, Sonnen A, Upton A, Salinsky M, Ristanovic R, Bergen $\mathrm{D}$, et al: A randomized controlled trial of chronic vagus nerve stimulation for treatment of medically intractable seizures. Neurology 45:224-230, 1995

22. Hallböök T, Lundgren J, Stjernqvist K, Blennow G, Strömblad LG, Rosén I: Vagus nerve stimulation in 15 children with therapy resistant epilepsy; its impact on cognition, quality of life, behaviour and mood. Seizure 14:504-513, 2005

23. Handforth A, DeGiorgio CM, Schachter SC, Uthman BM, Naritoku DK, Tecoma ES, et al: Vagus nerve stimulation therapy for partial-onset seizures: a randomized active-control trial. Neurology 51:48-55, 1998

24. Harden CL, Pulver MC, Ravdin LD, Nikolov B, Halper JP, Labar DR: A pilot study of mood in epilepsy patients treated with vagus nerve stimulation. Epilepsy Behav 1:93-99, 2000

25. Helmers SL, Wheless JW, Frost M, Gates J, Levisohn P, Tardo $\mathrm{C}$, et al: Vagus nerve stimulation therapy in pediatric patients with refractory epilepsy: retrospective study. J Child Neurol 16:843-848, 2001

26. Hornig GW, Murphy JV, Schallert G, Tilton C: Left vagus nerve stimulation in children with refractory epilepsy: an update. South Med J 90:484-488, 1997

27. Jambaqué I, Chiron C, Dumas C, Mumford J, Dulac O: Mental and behavioural outcome of infantile epilepsy treated by vigabatrin in tuberous sclerosis patients. Epilepsy Res 38:151160,2000

28. Jarrar RG, Buchhalter JR, Raffel C: Long-term outcome of epilepsy surgery in patients with tuberous sclerosis. Neurology 62:479-481, 2004

29. Kwan P, Brodie MJ: Early identification of refractory epilepsy. N Engl J Med 342:314-319, 2000

30. Levy ML, Levy KM, Hoff D, Amar AP, Park MS, Conklin $\mathrm{JM}$, et al: Vagus nerve stimulation therapy in patients with autism spectrum disorder and intractable epilepsy: results from the vagus nerve stimulation therapy patient outcome registry. Clinical article. J Neurosurg Pediatr 5:595-602, 2010

31. Loddenkemper T, Holland KD, Stanford LD, Kotagal P, Bingaman W, Wyllie E: Developmental outcome after epilepsy surgery in infancy. Pediatrics 119:930-935, 2007

32. Majoie HJ, Berfelo MW, Aldenkamp AP, Evers SM, Kessels AG, Renier WO: Vagus nerve stimulation in children with therapy-resistant epilepsy diagnosed as Lennox-Gastaut syndrome: clinical results, neuropsychological effects, and costeffectiveness. J Clin Neurophysiol 18:419-428, 2001

33. Major P, Thiele EA: Vagus nerve stimulation for intractable epilepsy in tuberous sclerosis complex. Epilepsy Behav 13: 357-360, 2008

34. McHugh JC, Singh HW, Phillips J, Murphy K, Doherty CP, Delanty N: Outcome measurement after vagal nerve stimulation therapy: proposal of a new classification. Epilepsia 48: 375-378, 2007

35. McLachlan RS, Sadler M, Pillay N, Guberman A, Jones M, Wiebe S, et al: Quality of life after vagus nerve stimulation for intractable epilepsy: is seizure control the only contributing factor? Eur Neurol 50:16-19, 2003

36. Murphy JV: Left vagal nerve stimulation in children with medically refractory epilepsy. J Pediatr 134:563-566, 1999

37. Murphy JV, Hornig G, Schallert G: Left vagal nerve stimulation in children with refractory epilepsy. Preliminary observations. Arch Neurol 52:886-889, 1995

38. Murphy JV, Torkelson R, Dowler I, Simon S, Hudson S: Vagal nerve stimulation in refractory epilepsy: the first 100 patients receiving vagal nerve stimulation at a pediatric epilepsy center. Arch Pediatr Adolesc Med 157:560-564, 2003

39. Oka E, Ohtsuka Y, Yoshinaga H, Murakami N, Kobayashi K, Ogino T: Prevalence of childhood epilepsy and distribution of epileptic syndromes: a population-based survey in Okayama, Japan. Epilepsia 47:626-630, 2006

40. Parain D, Penniello MJ, Berquen P, Delangre T, Billard C, Murphy JV: Vagal nerve stimulation in tuberous sclerosis complex patients. Pediatr Neurol 25:213-216, 2001

41. Patwardhan RV, Stong B, Bebin EM, Mathisen J, Grabb PA: Efficacy of vagal nerve stimulation in children with medically refractory epilepsy. Neurosurgery 47:1353-1358, 2000

42. Renfroe JB, Wheless JW: Earlier use of adjunctive vagus nerve stimulation therapy for refractory epilepsy. Neurology 59 (6 Suppl 4):S26-S30, 2002

43. Rossignol E, Lortie A, Thomas T, Bouthiller A, Scavarda D, Mercier C, et al: Vagus nerve stimulation in pediatric epileptic syndromes. Seizure 18:34-37, 2009

44. Rychlicki F, Zamponi N, Cesaroni E, Corpaci L, Trignani R, Ducati A, et al: Complications of vagal nerve stimulation for epilepsy in children. Neurosurg Rev 29:103-107, 2006

45. Shahwan A, Bailey C, Maxiner W, Harvey AS: Vagus nerve stimulation for refractory epilepsy in children: more to VNS than seizure frequency reduction. Epilepsia 50:1220-1228, 2009 
46. Sillanpää M, Schmidt D: Natural history of treated childhood-onset epilepsy: prospective, long-term population-based study. Brain 129:617-624, 2006

47. Smyth MD, Tubbs RS, Bebin EM, Grabb PA, Blount JP: Complications of chronic vagus nerve stimulation for epilepsy in children. J Neurosurg 99:500-503, 2003

48. Spencer S, Huh L: Outcomes of epilepsy surgery in adults and children. Lancet Neurol 7:525-537, 2008

49. Thompson PJ, Duncan JS: Cognitive decline in severe intractable epilepsy. Epilepsia 46:1780-1787, 2005

50. Uthman BM, Reichl AM, Dean JC, Eisenschenk S, Gilmore $\mathrm{R}$, Reid S, et al: Effectiveness of vagus nerve stimulation in epilepsy patients: a 12-year observation. Neurology 63:11241126, 2004

51. Waaler PE, Blom BH, Skeidsvoll H, Mykletun A: Prevalence, classification, and severity of epilepsy in children in western Norway. Epilepsia 41:802-810, 2000

52. Zamponi N, Rychlicki F, Cardinali C, Luchetti A, Trignani R,
Ducati A: Intermittent vagal nerve stimulation in paediatric patients: 1-year follow-up. Childs Nerv Syst 18:61-66, 2002

53. Zamponi N, Rychlicki F, Corpaci L, Cesaroni E, Trignani R: Vagus nerve stimulation (VNS) is effective in treating catastrophic 1 epilepsy in very young children. Neurosurg Rev 31:291-297, 2008

54. Zaroff CM, Morrison C, Ferraris N, Weiner HL, Miles DK, Devinsky O: Developmental outcome of epilepsy surgery in tuberous sclerosis complex. Epileptic Disord 7:321-326, 2005

Manuscript submitted November 5, 2010.

Accepted February 21, 2011.

Address correspondence to: Robert E. Elliott, M.D., Department of Neurosurgery, Bellevue Hospital Medical Center, 462 First Avenue, Suite 7S-4, New York, New York 10016. email: robert. elliott@nyumc.org. 